\title{
Decay heat power of spent nuclear fuel of power reactors with high burnup at long-term storage
}

\author{
Mikhail Ternovykh ${ }^{1}$, Georgy Tikhomirov ${ }^{1,{ }^{*}}$, Ivan Saldikov ${ }^{1}$ and Alexander Gerasimov ${ }^{2}$ \\ ${ }^{1}$ National Research Nuclear University MEPhI (Moscow Engineering Physics Institute), Department of Theoretical and Experimental Physics \\ of Nuclear Reactors, 31, Kashirskoye shosse, 115409, Moscow, Russia \\ ${ }^{2}$ Institute for Theoretical and Experimental Physics, Department of safe nuclear reactors, 25, Bolshaya Cheremushkinskaya ul., 117218, \\ Moscow, Russia
}

\begin{abstract}
Decay heat power of actinides and fission products from spent nuclear fuel of power VVER-1000 type reactors at long-term storage is calculated. Two modes of storage are considered: mode in which single portion of actinides or fission products is loaded in storage facility, and mode in which actinides or fission products from spent fuel of one VVER reactor are added every year in storage facility during 30 years and then accumulated nuclides are stored without addition new nuclides. Two values of fuel burnup 40 and $70 \mathrm{MW} \cdot \mathrm{d} / \mathrm{kg}$ are considered for the mode of storage of single fuel unloading. For the mode of accumulation of spent fuel with subsequent storage, one value of burnup of $70 \mathrm{MW} \cdot \mathrm{d} / \mathrm{kg}$ is considered. Very long time of storage $10^{5}$ years accepted in calculations allows to simulate final geological disposal of radioactive wastes. Heat power of fission products decreases quickly after 50-100 years of storage. The power of actinides decreases very slow. In passing from 40 to $70 \mathrm{MW} \cdot \mathrm{d} / \mathrm{kg}$, power of actinides increases due to accumulation of higher fraction of ${ }^{244} \mathrm{Cm}$. These data are important in the back end of fuel cycle when improved cooling system of the storage facility will be required along with stronger radiation protection during storage, transportation and processing.
\end{abstract}

\section{Introduction}

At present, safe nuclear thermal-neutron power reactors operating on uranium or uranium-plutonium fuel are used in nuclear power engineering of leading countries. Spent fuel is stored and accumulated in special storage facilities. During last tens years, advanced fuel with high burnup was developed and introduced in practice of nuclear power plants with light-water reactors. High burnup allows to increase economic efficiency of nuclear power plants and to decrease consumption of uranium. However application of nuclear fuel with high burnup influences strongly the back end of nuclear fuel cycle including interim and long-term storage of spent fuel, chemical processing, and ultimate disposal of radioactive wastes. Spent fuel of this type contains increased amount of high active actinides and fission products in comparison with common-type spent fuel. Therefore extended time of storage, improved cooling system of the storage facility will be required along with stronger radiation protection during storage, transportation and processing.

The main type of thermal-neutron power reactors in the world are light water reactors. Russian light water power reactors are named as VVER. They are the most commonly used in Russian nuclear power.

Typical burnup of fuel of VVER-1000 reactors was $40 \mathrm{MW} \cdot \mathrm{d} / \mathrm{kg} \mathrm{U}$ during recent years. Now prospective fuel is studied which ensure increased burnup up to 70 $\mathrm{MW} \cdot \mathrm{d} / \mathrm{kg}$.

The promising area is going to the closed fuel cycle, in which the natural nuclear fuel and the artificial fissionable materials produced as a result of reactor operation (plutonium and the like) are used to a much more complete extent. Fast nuclear reactors should be the base of closed fuel cycle. The burnup of the nuclear fuel in fast reactors is several times higher than in thermal neutron reactors. This leads to a respective increase in the fission products and minor actinides buildup both in the reactor core and in the spent nuclear fuel. High-active actinides and fission products are accumulated in spent fuel in the process of burnup. They determine the decay heat power and gamma-radiation during subsequent storage, transportation, reprocessing. Short-lives nuclides decay during the short interim storage in several years after the discharge. Therefore nuclides with half-life longer than 10 years present the most radiation danger. These nuclides are ${ }^{90} \mathrm{Sr},{ }^{137} \mathrm{Cs}$, ${ }^{244} \mathrm{Cm},{ }^{238} \mathrm{Pu},{ }^{241} \mathrm{Am}$.

Decay heat power of actinides and fission products from spent nuclear fuel of power VVER-1000 type reactors at long-term storage is studied in this paper. Calculated data for two fuel burnups 40 and $70 \mathrm{MW} \cdot \mathrm{d} / \mathrm{kg}$ are discussed. Two modes of storage are considered: mode in which single portion of actinides or fission products is loaded in storage facility, and mode in which

\footnotetext{
Corresponding author: GVTikhomirov@,mephi.ru
} 
actinides or fission products from spent fuel of one VVER reactor are added every year in storage facility during 30 years and then accumulated nuclides are stored without addition new nuclides.

\section{Annual unloading of americium and curium isotopes from the VVER-1000 reactor}

The masses of important fission products ${ }^{90} \mathrm{Sr}$ и ${ }^{137} \mathrm{Cs}$ along with long-lived ${ }^{99} \mathrm{Tc}$ and ${ }^{126} \mathrm{Sn}$ in annual discharge of the VVER are mainly the function of the power produced rather than of the mode of burnup. On the contrary, the quantity of the annually discharged different minor actinides increases in different ways with the burnup increase.

We calculated isotopic composition of spent fuel of VVER-1000 type reactor for burnup from 40 to 70 $\mathrm{MW} \cdot \mathrm{d} / \mathrm{kg}$. Initial enrichment $4.4 \%$ was accepted for burnup of $40 \mathrm{MW} \cdot \mathrm{d} / \mathrm{kg}$ with corresponding enrichment increase for higher burnup. Calculations were made using MCU, ORIGEN-SCALE codes [1-6]. Decay heat power in storage facility was calculated separately for actinides and fission products. Isotopes of neptunium, plutonium, americium, and curium were meant as actinides. We assumed that these isotopes were placed into storage facility as actinides, while uranium isotopes extracted from spent fuel in the chemical processing were returned into fuel cycle. Additionally, plutonium isotopes were produced as result of transformations of initial americium and curium isotopes. Power of alpha, beta, and gamma-radiation was taken for calculation of the decay heat power. Data on energy release in alpha and beta decays were taken from $[7,8]$.

Results of calculations of the main actinide masses from the annual discharge of the VVER-1000[9,10] reactor for the burnup of $40-70 \mathrm{MW} \cdot \mathrm{d} / \mathrm{kg}$ are presented in Table 1 and are illustrated in the Figure 1 for more wide limits of burnup.

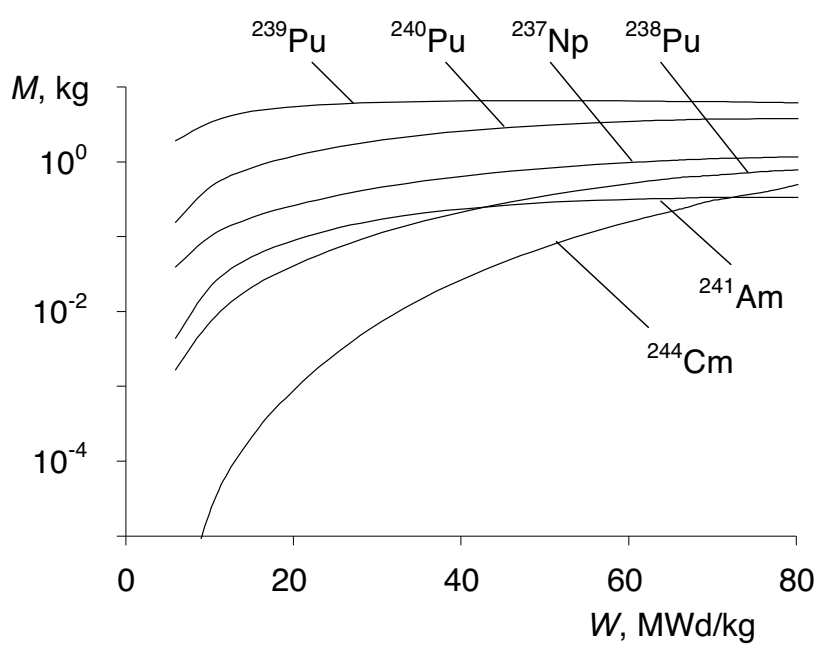

Fig. 1. Masses of main actinides in spent fuel of VVER-1000 reactor at different burnup of fuel
Table 1. Calculated data on annual unloading of actinides from VVER-1000 reactor at different burnup $B, \mathrm{~kg} /$ year

\begin{tabular}{|c|c|c|c|c|}
\hline \multirow{2}{*}{ Nuclide } & \multicolumn{4}{|c|}{$B, \mathrm{MW} \cdot \mathrm{d} / \mathrm{kg}$} \\
\cline { 2 - 5 } & 40 & 50 & 60 & 70 \\
\hline${ }^{237} \mathrm{~Np}$ & 14.4 & 14.8 & 14.6 & 14.0 \\
${ }^{238} \mathrm{Pu}$ & 4.93 & 6.57 & 7.90 & 8.74 \\
${ }^{239} \mathrm{Pu}$ & 146 & 117 & 96.7 & 81.3 \\
${ }^{240} \mathrm{Pu}$ & 57.2 & 55.1 & 51.8 & 47.8 \\
${ }^{241} \mathrm{Pu}$ & 28.2 & 26.9 & 24.8 & 22.4 \\
${ }^{242} \mathrm{Pu}$ & 11.8 & 15.5 & 18.6 & 21.3 \\
${ }^{241} \mathrm{Am}$ & 5.25 & 5.10 & 4.73 & 4.27 \\
${ }^{243} \mathrm{Am}$ & 2.19 & 3.57 & 4.96 & 6.14 \\
${ }^{242} \mathrm{Cm}$ & 0.0029 & 0.0038 & 0.0044 & 0.0045 \\
${ }^{243} \mathrm{Cm}$ & 0.0063 & 0.0106 & 0.0144 & 0.0175 \\
${ }^{244} \mathrm{Cm}$ & 0.529 & 1.17 & 2.09 & 3.27 \\
\hline
\end{tabular}

These data demonstrate that the increase of burnup from 40 to $70 \mathrm{MW} \cdot \mathrm{d} / \mathrm{kg}$ results in the corresponding increase of annual unloading of ${ }^{238} \mathrm{Pu}$ by 1.8 times while the mass of ${ }^{244} \mathrm{Cm}$ increases by 6.2 times.

\section{Decay heat power of fission products and actinides from single unloading of spent fuel of VVER-1000 reactor in long- term storage}

Calculated decay heat power of main fission products and actinides from 1 ton of spent fuel of VVER-1000 reactor with burnup of 40 and $70 \mathrm{MW} \cdot \mathrm{d} / \mathrm{kg}$ at long-term storage during the time $T$ is presented in Tables 2 and 3 . We assumed that initial moment of storage corresponded to the end of 3-year cooling after unloadung from the reactor. We considered ${ }^{237} \mathrm{~Np},{ }^{238} \mathrm{Pu},{ }^{239} \mathrm{Pu},{ }^{240} \mathrm{Pu},{ }^{241} \mathrm{Pu}$, ${ }^{242} \mathrm{Pu},{ }^{241} \mathrm{Am},{ }^{243} \mathrm{Am},{ }^{242} \mathrm{Cm},{ }^{243} \mathrm{Cm}$, and ${ }^{244} \mathrm{Cm}$ as actinides initially loaded in storage facility. Analogously, initialy loaded fission products were ${ }^{90} \mathrm{Sr},{ }^{99} \mathrm{Tc},{ }^{106} \mathrm{Ru}$, ${ }^{125} \mathrm{Sb},{ }^{126} \mathrm{Sn},{ }^{137} \mathrm{Cs},{ }^{144} \mathrm{Ce},{ }^{154} \mathrm{Eu},{ }^{155} \mathrm{Eu}$.

We considered such very long time of storage $10^{5}$ years which allows to simulate final geological disposal of radioactive wastes.

These data demonstrate that sum power of actinides in the initial period of storage increases by 4.6 times in going from burnup of 40 to burnup of $70 \mathrm{MW} \cdot \mathrm{d} / \mathrm{kg}$. This is explained by the fact that power of actinides is first of all due to high-active nuclide ${ }^{244} \mathrm{Cm}$, and secondly due to ${ }^{238} \mathrm{Pu}$ and ${ }^{241} \mathrm{Am}$. Analogously sum power of fission products in the beginning of storage increases by 1.5 times when passing from 40 to $70 \mathrm{MW} \cdot \mathrm{d} / \mathrm{kg}$. This is 
explained by the fact that power of fission products is due to respectively long-lived nuclides ${ }^{90} \mathrm{Sr}$ and ${ }^{137} \mathrm{Cs}$ with half-life about 30 years, and due to more short-lived nuclides ${ }^{144} \mathrm{Ce}$ and ${ }^{106} \mathrm{Ru}$.

Table 2. Calculated decay heat power $P$ of actinides and fission products FP at long-term storage for burnup of 40 $\mathrm{MW} \cdot \mathrm{d} / \mathrm{kg} \mathrm{U}$

\begin{tabular}{|c|c|c|c|}
\hline \multirow{2}{*}{$T}$, & \multicolumn{3}{|c|}{$P, \mathrm{~W}$} \\
\cline { 2 - 4 } year & Actinides & FP & Total \\
\hline 1 & 258 & 1950 & 2210 \\
10 & 264 & 960 & 1220 \\
100 & 220 & 110 & 330 \\
1000 & 64 & 0.03 & 64 \\
10000 & 15 & 0.02 & 15 \\
100000 & 0.85 & 0.01 & 0.86 \\
\hline
\end{tabular}

Table 3. Calculated decay heat power $P$ of actinides and fission products FP at long-term storage for burnup of 70 $\mathrm{MW} \cdot \mathrm{d} / \mathrm{kg} \mathrm{U}$

\begin{tabular}{|c|c|c|c|}
\hline \multirow{2}{*}{$T}$, & \multicolumn{3}{|c|}{$P, \mathrm{~W}$} \\
\cline { 2 - 4 } year & Actinides & FP & Total \\
\hline 1 & 1180 & 2990 & 4170 \\
10 & 890 & 1540 & 2430 \\
100 & 440 & 180 & 620 \\
1000 & 90 & 0.06 & 90 \\
10000 & 21 & 0.04 & 21 \\
100000 & 1.6 & 0.02 & 1.6 \\
\hline
\end{tabular}

The power of fission products in the beginning of storage exceeds the power of actinides by 7 times for burnup of $40 \mathrm{MW} \cdot \mathrm{d} / \mathrm{kg}$ and by 2.5 times for burnup of $70 \mathrm{MW} \cdot \mathrm{d} / \mathrm{kg}$. The power of fission products decreases quickly after 50-100 years of storage. So, for burnup of $40 \mathrm{MW} \cdot \mathrm{d} / \mathrm{kg}$ the power of fission products decreases by 3.3 times after 30 years, by 18 times after 100 years, by 1900 times after 300 years of storage. These data are about the same for burnup of $70 \mathrm{MW} \cdot \mathrm{d} / \mathrm{kg}$.

The power of actinides decreases very slowly in the process of storage because of the long half-life of the main actinides. So, for burnup of $40 \mathrm{MW} \cdot \mathrm{d} / \mathrm{kg}$ the power of actinides is practically flat during the first 100 years of storage, decreases by 4 times after 1000 years, by 17 times after 10000 years of storage. For burnup of 70 $\mathrm{MW} \cdot \mathrm{d} / \mathrm{kg}$ the power of actinides decreases by 2.7 times during the first 100 years of storage, by 13 times after 1000 years, by 56 times after 10000 years of storage.

The power of actinides makes equal to the power of fission products after 40-50 years of storage. At higher times of storage, the power of actinides far exceeds that of fission products.

Figures 2 and 3 demonstrate decay heat power of separate fission products for fuel burnup 40 and 70 $\mathrm{MW} \cdot \mathrm{d} / \mathrm{kg}$ during long-term storage. Figures 4 and 5 present decay heat power of separate actinides for burnup 40 and $70 \mathrm{MW} \cdot \mathrm{d} / \mathrm{kg}$. Figure 6 shows the power of gamma-radiation of actinides for burnup of 70 $\mathrm{MW} \cdot \mathrm{d} / \mathrm{kg}$.

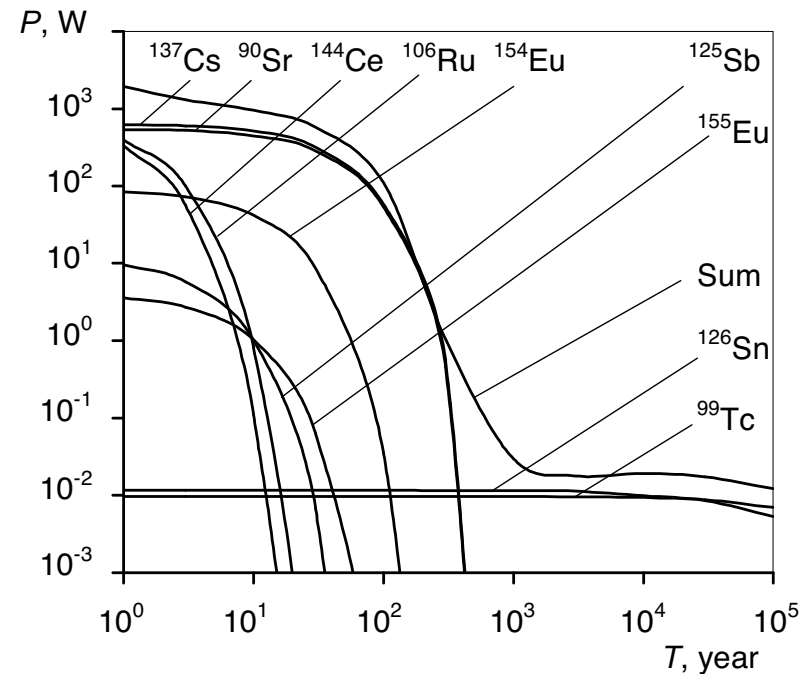

Fig. 2. Decay heat power of fission products from 1 ton of spent fuel of VVER-1000 reactor for fuel burnup $40 \mathrm{MW} \cdot \mathrm{d} / \mathrm{kg}$ at long-term storage

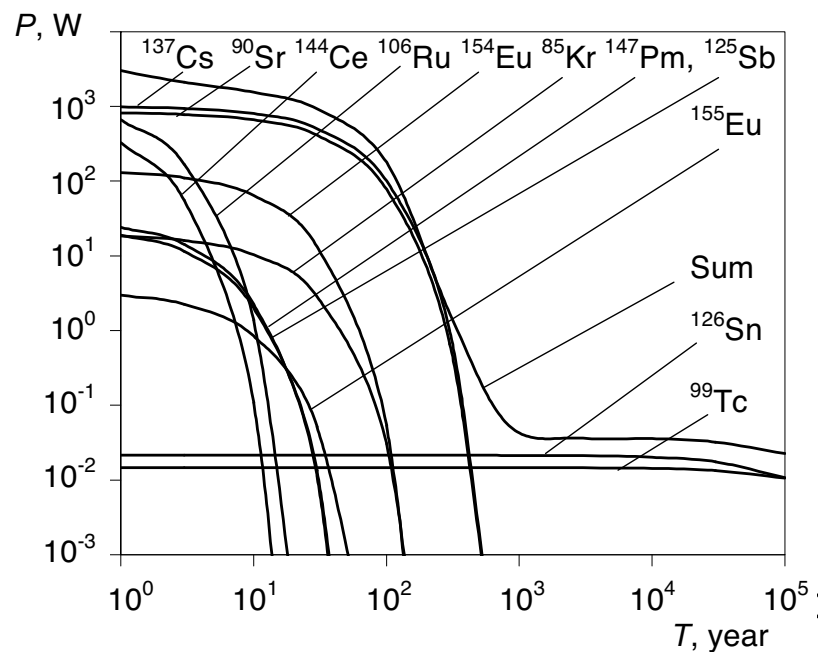

Fig. 3. Decay heat power of fission products from 1 ton of spent fuel of VVER-1000 reactor for fuel burnup $70 \mathrm{MW} \cdot \mathrm{d} / \mathrm{kg}$ at long-term storage 


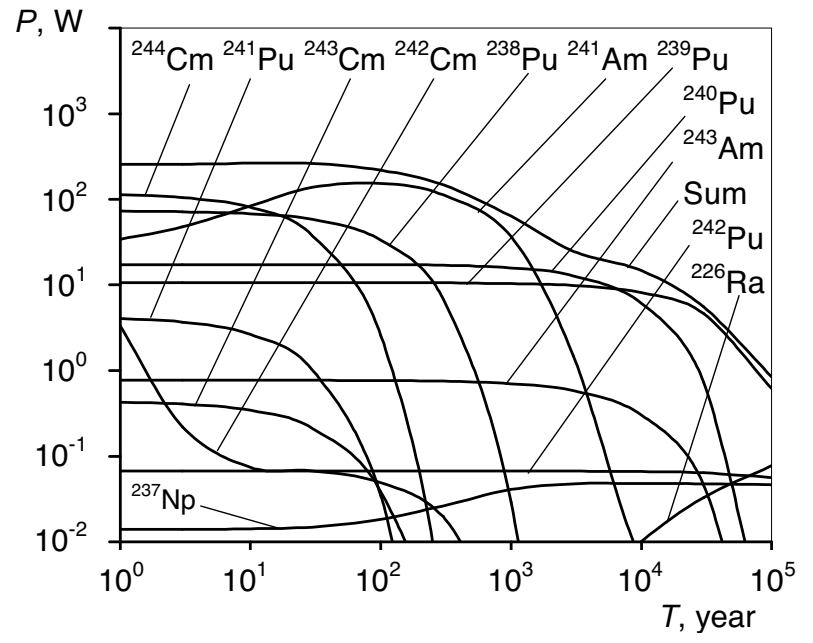

Fig. 4. Decay heat power of actinides from 1 ton of spent fuel of VVER-1000 reactor for fuel burnup $40 \mathrm{MW} \cdot \mathrm{d} / \mathrm{kg}$ at longterm storage

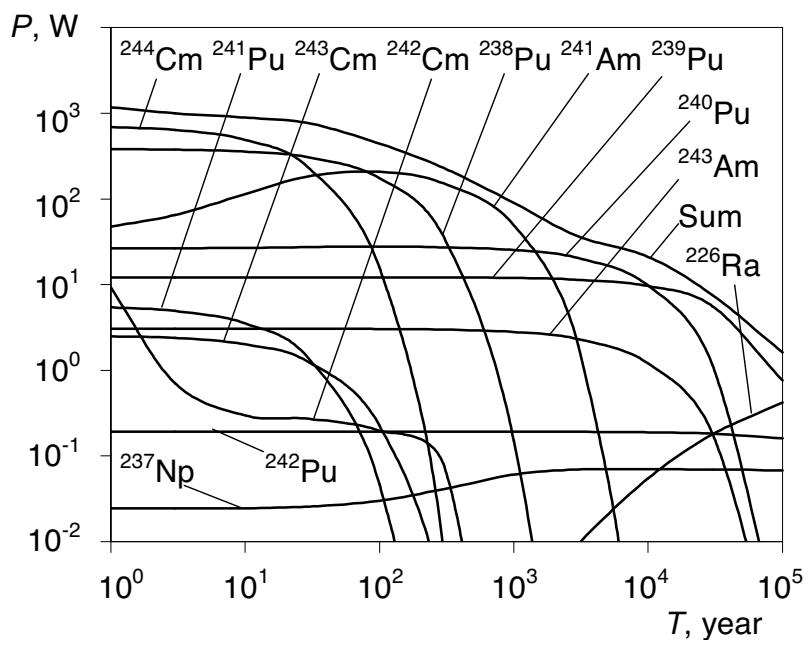

Fig. 5. Decay heat power of actinides from 1 ton of spent fuel of VVER-1000 reactor for fuel burnup $70 \mathrm{MW} \cdot \mathrm{d} / \mathrm{kg}$ at longterm storage

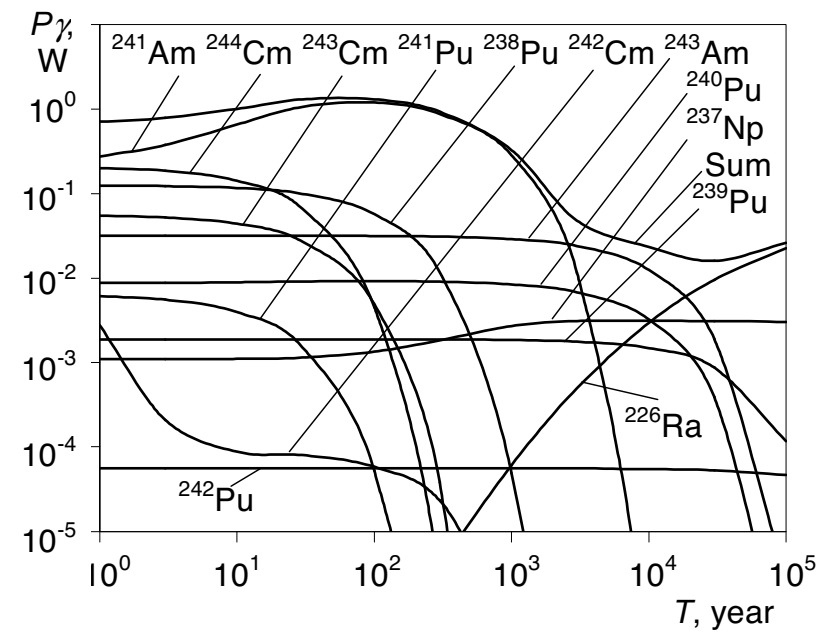

Fig. 6. Power of gamma-radiation of actinides from 1 ton of spent fuel of VVER-1000 reactor for fuel burnup $70 \mathrm{MW} \cdot \mathrm{d} / \mathrm{kg}$ at long-term storage

\section{Decay heat power of fission products and actinides from spent fuel of VVER- 1000 reactor for accumulation and subsequent long-term storage}

Calculated data on decay heat power of separate fission products for the mode of accumulation and subsequent storage are presented on the Figure 7. Fuel burnup was equal to $70 \mathrm{MW} \cdot \mathrm{d} / \mathrm{kg}$. Analogous data for separate actinides are shown in the figure 8 . In the mode of accumulation, fission products or actinides from spent fuel of one VVER-1000 reactor are loaded into storage facility every year during 30 years. Then accumulation is finished. Accimilated nuclides are stored in the storage facility without addition other nuclides during the period of subsequent storage up to 100000 years. So very long time of storage $10^{5}$ years allows to simulate final geological disposal of radioactive wastes.

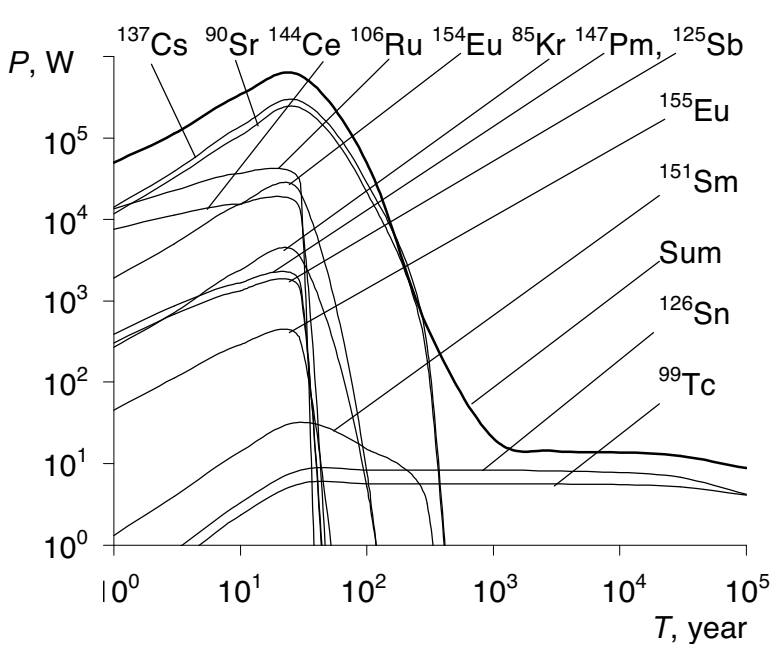

Fig. 7. Decay heat power of fission products in the mode of accumulation and subsequent long-term storage

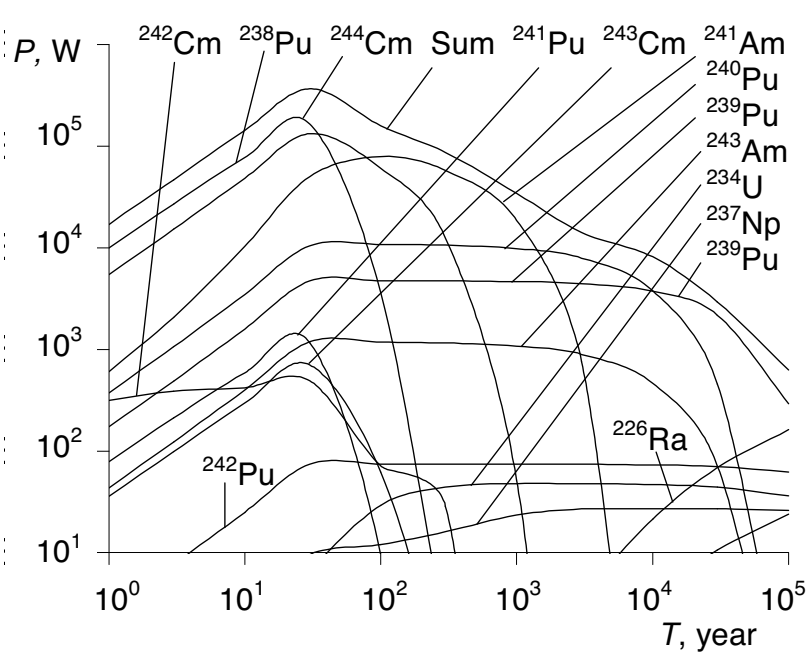

Fig. 8. Decay heat power of actinides in the mode of accumulation and subsequent long-term storage 
The decay heat power of actinides for the case when only isotopes of neptunium, americium, and curium were placed into storage facility in the period of accumulation is presented in Figure 9. In this case we assumed that isotopes of uranium and plutonium were returned in fuel cycle while isotopes of neptunium, americium, and curium were directed to storage. Calculations were performed for fuel burnup of $70 \mathrm{MW} \cdot \mathrm{d} / \mathrm{kg}$ and for the time of accumulation of 30 years.

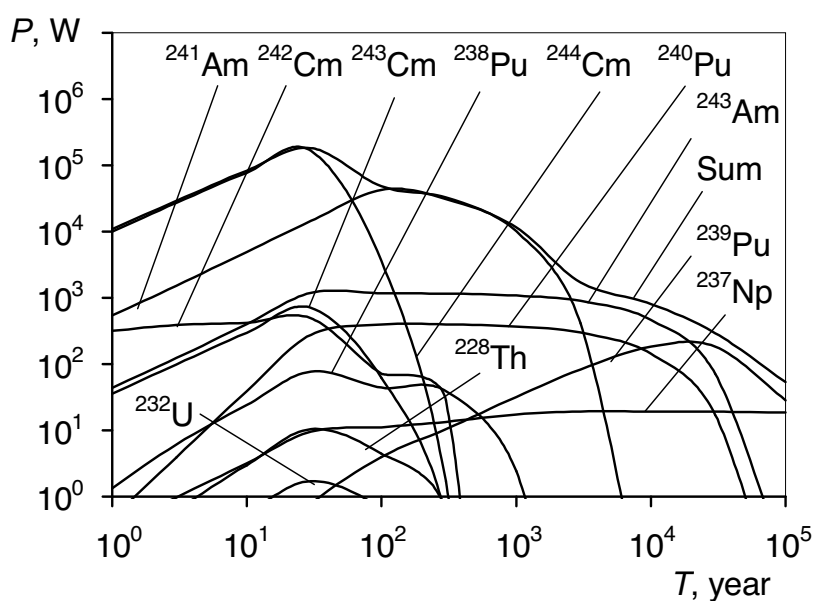

Fig. 9. Decay heat power of actinides in the mode of accumulation of neptunium, americium, and curium isotopes with subsequent long-term storage

\section{The discussion of the results}

The results presented above concerning to the long-term storage of fission products and actinides from single unloadung of spent fuel demonstrate the following.

Decay heat power of fission products (Figures 2 and 3 ) during the period of storage of about 30-300 years is mainly due to ${ }^{90} \mathrm{Sr}$ and ${ }^{137} \mathrm{Cs}$ with half-life periods of about 30 years. The other curves on Figures 2 and 3 correspond to more short-lived nuclides (except ${ }^{99} \mathrm{Tc}$ and ${ }^{126} \mathrm{Sn}$ ). Their contribution to the decay heat power decreases quickly. Nuclides ${ }^{90} \mathrm{Sr}$ and ${ }^{137} \mathrm{Cs}$ decay after about 300 years. The power decreases by 4-5 orders of magnitude to the end of this period of time. After the decay of ${ }^{90} \mathrm{Sr}$ and ${ }^{137} \mathrm{Cs}$, the long-lived ${ }^{99} \mathrm{Tc}$ and ${ }^{126} \mathrm{Sn}$ give the main share to the power.

When passing from fuel burnup 40 to $70 \mathrm{MW} \cdot \mathrm{d} / \mathrm{kg}$, the decay heat power of fission products increases by 1.5-1.6 times for the period of storage less than 100 years (due to ${ }^{90} \mathrm{Sr}$ and ${ }^{137} \mathrm{Cs}$ ), and by 2 times for the period of storage more than 1000 years (due to ${ }^{99} \mathrm{Tc}$ and $\left.{ }^{126} \mathrm{Sn}\right)$.

Decay heat power of actinides (Figures 4 and 5) is mainly due to ${ }^{244} \mathrm{Cm}$ during the first 30 years. After that, the power is mainly due to ${ }^{241} \mathrm{Am}$ and ${ }^{238} \mathrm{Pu}$ in the period of storage of 30-100 years. The main nuclide is ${ }^{241} \mathrm{Am}$ in the period of 100-1000 years. Then the main nuclides are ${ }^{240} \mathrm{Pu}$ in the period of $10^{3}-10^{4}$ years, and ${ }^{239} \mathrm{Pu}$ in more long period of time. Contribution of ${ }^{237} \mathrm{~Np}$ is negligible during the whole period of storage.
The power of gamma-radiation of actinides (Figure 6 ) is due to ${ }^{241} \mathrm{Am}$ during 5000 years of storage. After 30000 years of storage, the power of gamma-radiation is due to ${ }^{226} \mathrm{Ra}$, which was accumulated in storage as result of decays of other actinides.

Let's pass to the mode of accumulation and subsequent storage of fission products and actinides.

For the mode of accumulation of fission products in storage facility during 30 years, the power of fission products (Figure 7) icreases during the whole period of accumulation mainly due to ${ }^{90} \mathrm{Sr}$ and ${ }^{137} \mathrm{Cs}$. Contribution of other short-lived fission products is much less. After the end of the period of accumulation, decay heat power recreases smoothly by 6-7 orders of magnitude during following 1000 years due to decay of ${ }^{90} \mathrm{Sr}$ and ${ }^{137} \mathrm{Cs}$. After this period of time, the power decreases slowly due to very long lived nuclides ${ }^{99} \mathrm{Tc}$ and ${ }^{126} \mathrm{Sn}$.

Decay heat power of actinides in the mode of accumulation with subsequent storage (Figure 8) demonstrates the same time dependensy as for long-term storage of a single unloading. In the period of accumulation the power increases mainly due to accumulation of ${ }^{244} \mathrm{Cm}$ and ${ }^{238} \mathrm{Pu}$. After the end of the period of accumulation, the power decreases slowly due to decay of ${ }^{238} \mathrm{Pu}$, and then due to decay of ${ }^{241} \mathrm{Am},{ }^{240} \mathrm{Pu}$. The main nuclides are ${ }^{238} \mathrm{Pu}\left(50-100\right.$ years), ${ }^{241} \mathrm{Am}(100-$ 2000 years), ${ }^{240} \mathrm{Pu}\left(2000-10000\right.$ years), ${ }^{239} \mathrm{Pu}$ (more than 10000 years).

Maximum decay heat power of fission products exceeds by 1.6 times the maximum decay heat power of actinides. It approximately corresponds to the end of the period of accumulation.

When we accumulate only isotopes of neptunium, americium, and curium (Figure 9) then maximum power is about 2 times lower with respect to the power with account of accumulation of ${ }^{238} \mathrm{Pu}$ (Figure 8). ${ }^{241} \mathrm{Am}$ makes basic contribution to total decay heat power of actinides in this case. After 3000 years of storage, the nain isotop is ${ }^{243} \mathrm{Am}$, and then ${ }^{239} \mathrm{Pu}$, produced in transformations of other actinides.

\section{Conclusions}

These data allow us to estimate the decay heat power and the gamma radiation level in long-term storage facility. Simple calculations for storage with a period of accumulation of nuclides in long-term storage facility can be used to describe the increase of energy release in the period of accumulation of radioactive waste and the decrease of energy release during period of storage due to decay of the nuclides. So long-term storage period of 100000 years accepted for calculations allows to simulate final disposal of radioactive waste in geological formations.

In the period of accumulation in long-term storage, energy is determined mainly by fission products ${ }^{90} \mathrm{Sr}$ and ${ }^{137} \mathrm{Cs}$. These nuclides decay during about 300 years after the end of the accumulation period, while the power of the actinides reduces slowly. During storage without the addition of spent fuel, the decay heat power determines mainly by the actinides. After 1000 years of storage, the 
total energy release is reduced only by 15 times in comparison with the maximum energy corresponding to the end of the period of accumulation in storage. Gamma radiation in the period of accumulation is determined mainly by fission products. The power of the gamma radiation of fission products is 3-4 times lower than the total power of energy release of the fission products, and gamma radiation of actinides by several orders of magnitude lower than their total decay heat power.

The maximum decay heat power of actinides from spent uranium fuel with a burnup of $70 \mathrm{MW} \cdot \mathrm{day} / \mathrm{kg}$ is about four times higher than that of for uranium fuel with burnup of $40 \mathrm{MW} \cdot \mathrm{d} / \mathrm{kg}$ due to higher accumulation of ${ }^{244} \mathrm{Cm}$.

Thus, the use of fuel with high burnup may lead to a $50 \%$ increase in the total decay heat power of the fission products and actinides in long-term storage compared with common-type spent fuel. The fission products give a significant contribution to the total decay heat power only during the period of accumulation of spent fuel in long-term storage.

\section{References}

1. Kalugin, M.A., Oleynik, D.S., Shkarovsky, D.A. Annals of Nuclear Energy, Volume 82, 28 July 2015, Pages 54-62

2. SCALE: A Modular Code System for Performing Standardized Computer Analyses for Licensing Evaluation, Version 5, ORNL/TM-2005/39, I-III, ORNL (2005)

3. V.P. Alferov, A.I. Radaev, M. V. Shchurovskaya, G. V. Tikhomirov, N.A. Hanan, F.A. Van Heerden, Ann. Nucl. Energy 77 (2015) 273-280.

4. A.M. Sirotkin, M.Y. Ternovykh, G.V. Tikhomirov, M.F. Khromova, At. Energy 116 (2014).

5. A.S. Gerasimov, V.N. Kornoukhov, I.S. Sald'ikov, G.V. Tikhomirov, At. Energy 116 (2014).

6. D.N. Skorokhodov, G.V. Tikhomirov, Phys. At. Nucl. 75 (2012).

7. ICRP, 2008. Nuclear Decay Data for Dosimetric Calculations. ICRP Publication 107. Ann. ICRP 38 (3)

8. Brown, D.A. Nuclear Data Sheets. Volume 118, Issue 1, April 2014, Pages 98-103.

9. B.R. Bergelson, V.V. Belonog, A.S. Gerasimov, G.V. Tikhomirov, At. Energy 109 (2011).

10. B.R. Bergelson, V.V. Belonog, A.S. Gerasimov, G.V. Tikhomirov, At. Energy 107 (2009). 